\title{
Life Cycle Approaches to Sustainable Regional Development
}

\author{
Fritz Balkau and Timothy Grant
}

\begin{abstract}
Regional development that is truly sustainable depends on the adoption of systematic and long-term criteria for decision-making at different levels, taking into account the full life cycle of raw materials and products, as well as of infrastructure projects. This session invited the presentation of life cycle management applications from both a scientific and a practitioner point of view, highlighting examples and case studies at regional level. The applications are relevant to private actors from different economic sectors as well as for public representatives responsible for regional planning and administrative procedures.
\end{abstract}

\section{Introduction and Session Content}

Regional development that is truly sustainable depends on the adoption of systematic and long-term criteria for decision-making at different levels, taking into account the full life cycle of raw materials and products, as well as of infrastructure projects. This session invited the presentation of life cycle management applications from both a scientific and a practitioner point of view, highlighting examples and case studies at regional level. The applications are relevant to private actors from different economic sectors as well as for public representatives responsible for regional planning and administrative procedures.

Life cycle tools presented in this session included LCA, Materials Flow Analysis (MFA), supply-chain management, eco-design, environmental product declarations (EPD), and sustainable public purchasing (SPP). These were applied to a variety of industry sectors such as building and construction, chemicals production, agriculture and food, wood production. All the above life cycle tools are applicable at

\author{
F. Balkau ( $\square)$ \\ Sustainable Solutions, Paris, France \\ e-mail: fbalkau@gmail.com \\ T. Grant \\ Lifecycles Australia, Melbourne, Australia \\ (C) The Author(s) 2018 \\ E. Benetto et al. (eds.), Designing Sustainable Technologies, \\ Products and Policies, https://doi.org/10.1007/978-3-319-66981-6_48
}


regional level, with broad-scale applications into initiatives aimed at circular economy, bio-economy and fostering local industries.

The presenters reiterated that the systematic use of the above tools depends on an extensive programme of awareness-raising, education and training of both private and public sector actors, as well as the creation of collaborative partnerships that reach along the life chain of materials and programmes. All these need to be underpinned by adequate life cycle based databases and suitable metrics that allow assessments to be reliably performed. It is also useful to undertake pilot studies and compile case studies of successful initiatives.

\section{Appreciation of the Presentations}

The five presentations in this session described a variety of life cycle tools and methodologies. While each presentation was on a different subject, they nevertheless formed a complementary set of approaches that can be of use to regions in their pursuit of more sustainable forms of development. The case studies were drawn from five different regions around the world-France (2), Germany, Australia, South America (Peru), indicating that the use of life cycle tools for regional development has universal relevance.

Benoit Ribon gave an interesting presentation of territorial metabolism (or materials flows) in a north-eastern region in France (Alsace). Flows are calculated according to a set of internal nodes that are connected by materials and energy movements. This allows an estimation of internal consumption as well as of import and export volumes. Such an analysis provides information towards the design of a circular economy, and at a different level, the needs and options for local waste management.

The presentation described a model to calculate regional MFA, revealing the dynamics of resources in transit, waste management and internal (regional) production and consumption. All these have important sustainability implications. Concerning the management considerations, through an MFA both the energy sources as well as points of wastage can be more clearly identified, potentially allowing efficient intervention to improve the path towards regional sustainability.

The study also highlighted some constraints, in particular that imposed by the nomenclature of freight statistics. Freight is one of the few data sources at regional level relating to materials importation and exportation, however the structure of the data does not reflect well the life cycle of products. This inevitably leads to many assumptions in data processing and modelling. A direct conclusion is thus that regions themselves may need to ensure sufficient statistical data if they are to better understand their circular economy dynamics.

Timothy Grant described a recent study in the State of South Australia aimed at enhancing the circularity of materials flows to increase local employment, reduce energy use and improve materials efficiency while diminishing waste generation. The ensuing scenario development looked also at other benefits such as energy 
independence, entrepreneurship, and generally encouraging the evolution to more sustainable forms of business that favour use of local materials and labour. Greater reliance on renewable energy is an important centrepiece of the South Australian scenarios, compensating for the closure of fossil fuelled power stations there, and present use of fossil fuel for heating.

The use of MFA as illustrated in this presentation covered not only energy but also various materials flows that have implications for sustainability. The use of MFA gives greater reliability and certainty to scenario development, giving public policy makers more confidence in the various future visions that circular economy scenarios attempt to provide.

The implications of the materials flow calculations of the scenarios are now being evaluated by the Government with an expectation of early adoption and application.

Vanessa Pasquet described the life cycle management framework put in place by the French region 'Hauts de France' where various industry sectors become more deeply linked with their supply chains by using life cycle management procedures. These include methods such as environmental design, eco-labels, environmental product declarations (EPD) and advanced building standards. Similar tools can also be applied to other industry sectors such fisheries, agriculture, textiles among others.

Life cycle assessment provides much of the essential information on which the management tools are based. In view of the breadth of the sustainability agenda, a variety of LCA procedures may be necessary to capture all the key issues of regional concern. It is also important that all stakeholders along the value chains are identified during the LCA process to ensure adequate co-operation in implementation.

The life cycle management framework described by Pasquet is strongly oriented towards collective action rather than authoritarian regulation, although the latter is eventually needed to ensure that all players have the same targets. The building of stakeholder alliances depends on credible information (from the LCA process), identification of common objectives for all the stakeholders, effective metrics to measure progress and of remaining hotspots, communication procedures adapted to the needs of supply-chain stakeholders, and transparency in monitoring and reporting the outcomes. In many cases further education and training of supply-chain partners may be needed.

Sinéad O'Keefe described an initiative by the by the Helmholtz-Centre for Environmental Research GmbH-UFZ to model the industrial infrastructure and stakeholder collaborations necessary for greater use of locally sourced organic material (mainly wood products) in the eastern regions of Germany. The region already has an extensive chemicals industry based on imported raw materials (mainly gas) but also has extensive forest lands and agricultural outputs. The perspective of establishing a regional bio-economy as part of an industrial transformation process would have many advantages.

The study considers the sustainability and social impacts of a number of product mixes that could be based on a regional bio-economy rather than on imported materials as at present. Various life cycle assessment tools underpin this initiative; materials flow analysis, life cycle assessment, social impact assessment, and 
eco-footprint being the principal ones. Climate footprint was the main sustainability factor considered, however a full impact suite was taken into account to avoid possible burden shifting and spill-over effects.

It is likely that a fully-fledged move to transform the resource base of a regional economy will eventually require further tools as a supplement. Monitoring and evaluating the development of a regional bio-economy needs to take into account technical, social and environmental factors, as well as paying regard to employment conditions and local amenity objectives. Tools for some of these were developed as part of the initiative, and were applied to several scenarios of biomass sources, product mixes and social structures.

O'Keefe describes an integrated approach - the SUMINISTRO frameworkthat considers the above factors using methodologies based on both traditional and social LCA, evaluating the environmental and socio-economic impacts from different product mixes of the bio-economy(s) being modelled. The study concludes that an integrative assessment framework and knowledge base can indeed facilitate industrial transformation towards regional bio-economies based on local resources. The establishment of participative stakeholder networks helps to identify key opportunities and risk in such a transformation. A number of actual local case studies of biomass-derived products confirms the feasibility of this approach.

Ian Vázquez-Rowe. Consequential life cycle assessment methods can be used to evaluate the various environmental, social and economic consequences of public policy decisions for further development of regional agriculture. A particular preoccupation for agriculture these days is water use and climate change, not only in terms of adaptation but also for GHG generation from agriculture itself. Vázquez-Rowe presented an evaluation of potential agricultural developments in Peru, in particular for the growing of grapes for production of pisco (an alcoholic beverage made from grapes) for export. The market for this is expected to increase, making a sustainability (GHG and water) assessment very pertinent. Potential impacts have to be seen in the light of crop replacement and possible use of fallow land that do not require additional new lands to be brought into production. The study had to take into account questions of land-use, property markets, and the optimum way to allocate production under different economic and market scenarios. Nevertheless, not all parameters influencing farmers' decision could be included in the model. In the end it was found that there need not be an increase in net GHG emissions if appropriate farming practices were employed, but water use was dependent on the area farmed.

\section{Overview}

Individually, the presentations describe some interesting research and regional case studies. Several broke new ground in the application of life cycle tools at regional level, both in assessment and in LCM, as for example in social LCA related to bio-economy transformation in Germany. Several others described the relevance of 
standard LC tools to other regions that had not so far been highlighted in regional LCM work (e.g. MFA in Alsace, and LCA in Peru, respectively). Two presentations relating to South Australia and Hauts de France respectively, describe the application of life cycle management and circular economy principles by regional authorities to move their development policies forward.

This Session discussed extended LCA for new industrial situations, as well as the application of standard LCA and MFA to additional regions. Both are valuable in promoting the further use of life cycle methodologies in regions, echoing the conclusion of a recent book [1] that what is needed is both a further evolution of LC tools, and raising the profile of LCM among regional managers and policy makers. The utility of life cycle approaches to regional development is relevant to all continents as we saw, and it is encouraging that LCA societies are nowadays found in many countries. It remains to encourage these societies to take a broader view than simply refining the present assessment methodologies - they also need an eye on new client groups who have different needs.

\section{Future Perspectives}

Neither the development agenda nor the LCA environment is standing still. Regions and local governments are under increasing stakeholder and trade pressure, and are looking for ways to meet upcoming challenges, whether climate change, biodiversity loss, land preservation or social and employment issues. While certain life cycle techniques are occasionally used by regions, few base their future development on a systematic life cycle approach. This is particularly unfortunate at a time when many are experimenting with, for example, circular economy, industrial ecology, long-term infrastructure planning or 'sustainable' forms of manufacture and business. Now is the right formative moment for the life cycle community to open its doors to regional government as an important stakeholder and client group, to speak to them in their language, and to discuss their needs. The incorporation of a municipality in the recent road test of Organisational Life Cycle Assessment (O-LCA) [2] is a step (but only a small one) in the right direction. To borrow a phrase from other area, a dose of positive discrimination in the direction of the public sector would be a helpful move in enlarging the scope of LCA/LCM application.

At the same time the life cycle community could usefully accelerate the effort to further evolve life cycle methodologies that are of interest to regions, such as landscape and land-use assessment techniques, biodiversity assessment, natural resource accounting, eco-footprints and so on. There are embryonic moves in these areas - they could usefully be moved further along to mainstream level in conferences, teaching and research. 


\section{References}

1. Life cycle approaches to sustainable regional development, Balkau F, Massari S, Sonnemann G, eds., Taylor and Francis 2017.

2. Road testing Organizational Life Cycle Assessment around the world: Applications, experiences and lessons learned", http://www.lifecycleinitiative.org/download/6060.

Open Access This chapter is licensed under the terms of the Creative Commons Attribution 4.0 International License (http://creativecommons.org/licenses/by/4.0/), which permits use, sharing, adaptation, distribution and reproduction in any medium or format, as long as you give appropriate credit to the original author(s) and the source, provide a link to the Creative Commons license and indicate if changes were made.

The images or other third party material in this chapter are included in the chapter's Creative Commons license, unless indicated otherwise in a credit line to the material. If material is not included in the chapter's Creative Commons license and your intended use is not permitted by statutory regulation or exceeds the permitted use, you will need to obtain permission directly from the copyright holder.

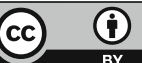

